\title{
Health impacts of extreme events
}

\author{
Safieh Javadinejad $^{1} \cdot$ Rebwar Dara $^{2} \cdot$ Forough Jafary $^{3}$
}

Received: 16 October 2019 / Revised: 11 March 2020 / Accepted: 13 March 2020 / Published online: 9 April 2020

(C) The Author(s) 2020

\begin{abstract}
Urbanization and urban development, along with the acceleration of population growth, the development of industrial activities or the consumption of fossil fuels has greatly increased the air pollution, with the consequences of it being, in the first place, a variety of diseases and respiratory illnesses, exacerbations of cardiovascular, pulmonary, skin diseases, etc. The inhabitants of cities are noticed. On the other hand, climatic parameters such as humidity, sunshine hours, temperature, and pressure and the amount of solar radiation increases the amount of pollutants in the atmosphere and increases the coefficient of their effect on humans and natural ecosystems. Therefore, by altering the composition of effective gases in the life of the earth's organisms and disturbing their balance, humans injure themselves and the environment, causing wide variations in the climate patterns of the earth, and on the other hand their health and well-being put at risk. In this paper, the relationship between climatic elements with the various diseases in Khoozestan province has been investigated (suspended PM). For this purpose, after the data collection, statistical calculations were carried out and the results were presented as tables and charts and the relationship between one variables with patients were examined. The results show that there is a significant and strong correlation between climatic elements such as temperature, precipitation with several disease.
\end{abstract}

Keywords Health $\cdot$ Climate $\cdot$ Effects $\cdot$ Disease $\cdot$ Development

\section{Introduction}

Man from a distant past, although not familiar with the term pathological geography. But he knew that some of the climatic phenomena are contributing to the disease. Cold, heat, humidity, pressure difference and wind are among the factors that are nowadays considered in medical geography. In this science,

Safieh Javadinejad

nsofiya65@gmail.com

Rebwar Dara

rebwar.dara@knowledge.ed.u.krd

Forough Jafary

foroughjafary@yahoo.com

1 Water Resource Engineering, University of Birmingham, Edgbaston St., Birmingham B152TT, UK

2 Hydrogeology, University of Birmingham, Edgbaston St., Birmingham B152TT, UK

3 Water Resource Management, University of Birmingham, Edgbaston St., Birmingham B152TT, UK we study the relationships between climate phenomena on the planet and the causes of disease dispersion and discover their causal relationships. On the other hand, climate parameters exacerbate the amount of pollutants in the atmosphere and increase their impact on humans and natural ecosystems. Hence, human beings have been damaging themselves and the environment by altering the combination of effective gases in the life of the earth's organisms and disturbing their balance, causing climate change and putting their health at risk (Wu et al. 2016)..

Since the late nineteenth century, the average temperature of the earth has risen by about $5.0{ }^{\circ} \mathrm{C}$. Some scientists believe that the Earth's average temperature rises between $1{ }^{\circ} \mathrm{C}$ and $6^{\circ} \mathrm{C}$ by 2100 (Mills et al. 2018). This increase in temperature will cause sudden changes in the global climate. The warming of the earth is damaging to the lives of humans. Outbreaks of unknown diseases include these injuries (Analitis et al. 2018)..

Scientists at the World Health Organization (WHO) believe that rising global temperatures could lead to a spread of malaria, yellow fever, bone loss, respiratory diseases and other diseases (Buchner et al. 2018). The spread of these diseases, grow more in warm and humid environments. Its pathogenic agents also survive in warm and humid conditions. 
Awareness of the geographical distribution of illnesses for each country's health planning is required to inform the authorities about the situation of each disease in the whole world and in different regions of the country and to include the necessary health measures for residents of the areas in their health policies.

The medical geography, also referred to as the geography of health, is a new and important area of health research, a link between geography and the geographic aspect of health. Geomedical health studies the effects of location and climate on the health of humans, and aims at understanding factors and variables that affect the health of the population and individuals. Because humans are always in direct contact with the climatic environment, this makes it possible to consider the way in which the organism reacts in the atmosphere. On the other hand, the growing trend of climate change and rising earth temperatures may make some diseases in the geographic regions affected by them. In fact, climatic conditions and natural barriers such as the oceans, on the one hand, and the dependence of some infectious agents on carriers and reservoirs, on the other hand, have limited certain diseases to certain parts of the planet (Vezzulli et al. 2016)..

In Iran (which is located in central Asia), the Alborz mountains in the north and the Zagros Mountains in the west have caused a variety of and even conflicting climatic conditions in the central parts of the country and in different parts of the country, causing a variety of animals and plants (like moose and wheat) get various diseases. Therefore, according to the studies, it can be said that in the province of Khoozestan, climate change and natural environment barriers, such as altitudes and deserts, correspond to the prevalence of regional or endemic diseases. Accordingly, the purpose of this study is to identify the relationship between climatic elements and the dispersal status of the deceased due to a variety of diseases in Khoozestan province. Also, this research seeks to answer the question of whether there is a meaningful relationship between the climatic elements of temperature, rainfall and altitude with the magnitude of various human diseases in the cities of Khoozestan province.

\section{Different diseases and relationships with climatic factors}

In this section the relationship between different extreme events and their impacts on health are explained with consider several aspects. Fig. 1 shows the relationship and analysis process.

\section{Definition of air pollution}

Air pollution is the presence of harmful substances in the air to a degree that Undesirable effects on the environment as a whole, including humans, plants, animals, Water, buildings and so on. Air pollution sources are divided into two natural and artificial categories as follows (Zhengdong et al. 2018):

A) Stimulant inflammatory substances: It has a caustic, blistering, and mucosal effect such as sulfur dioxide, ozone dioxide, nitrogen.

B) Shut-offs: Disrupt the oxidation of the tissue such as carbon dioxide, carbon monoxide.

C) Anesthetists and opiates: Like hydrocarbons.

D) Systemic Toxins: Damage to hematopoiesis (benzene) injuries.

Organic (halogenated hydrocarbons) - The formation of neural toxins (dual carbon sulfide) - toxic metal (lead) - toxic nonmetallic minerals (phosphorus).

\section{Gas pollutants and its influence on the prevalence of diseases}

Carbon monoxide: The gas is colorless and odorless and slightly lighter than air. More than half of the air pollution in large cities caused by this gas due to incomplete combustion of fuel in a motor vehicle. After reaching the upper atmosphere of the atmosphere, the gas is exposed to ultraviolet radiation of the sun and converted into carbonic anhydride. Carbon monoxide gas has a strong tendency to combine with hemoglobin, which results in the formation of carboxy hemoglobin, which reduces the capacity of the lungs (Ramadour et al. 2000). A person who is exposed to these gases, first excited after 20 min of his nervous system, suffers from headache, headache, nausea, weakness, darkness, and heart rate.

To determine the standard carbon monoxide, an average of eight hours has been used, which is $9 \mathrm{ppm}$. According to the statistical data of Khoozestan Environmental Organization, the rate of carbon monoxide pollution in center of the city is higher than other fields due to the heavy traffic of vehicles at this point of the city of Khoozestan.

Sulfur dioxide $\left(\mathrm{So}_{2}\right)$ : It mainly enters the atmosphere by using fossil fuels. This is a colorless gas that is dissolved in water and drops of rain and converted to sulfur oxide and sulfuric acid in the air. The acid comes down to the ground with rainwater and this type of precipitation is called acid rain.

Sulfuric acid in the atmosphere is mixed with smoke, soot and suspended particles, and it enters the respiratory tract into the lung glands, causing pathogenic lesions. On the other hand, it exacerbates anxiety and mental (illness Wei et al. 2019). Studies on human blood at the University of Arizona showed that sulfur dioxide reduces the amount of DNA and creates changes in chromosomes. Lymphocytes also disappear and the body's resistance to infectious diseases is reduced.

Due to the solubility of sulfur dioxide with water and consequently mucous membranes, pharynx and larynx, it has the greatest effect on the upper respiratory tract, but in the 
Fig. 1 Relationship between climate parameters and human health impacts

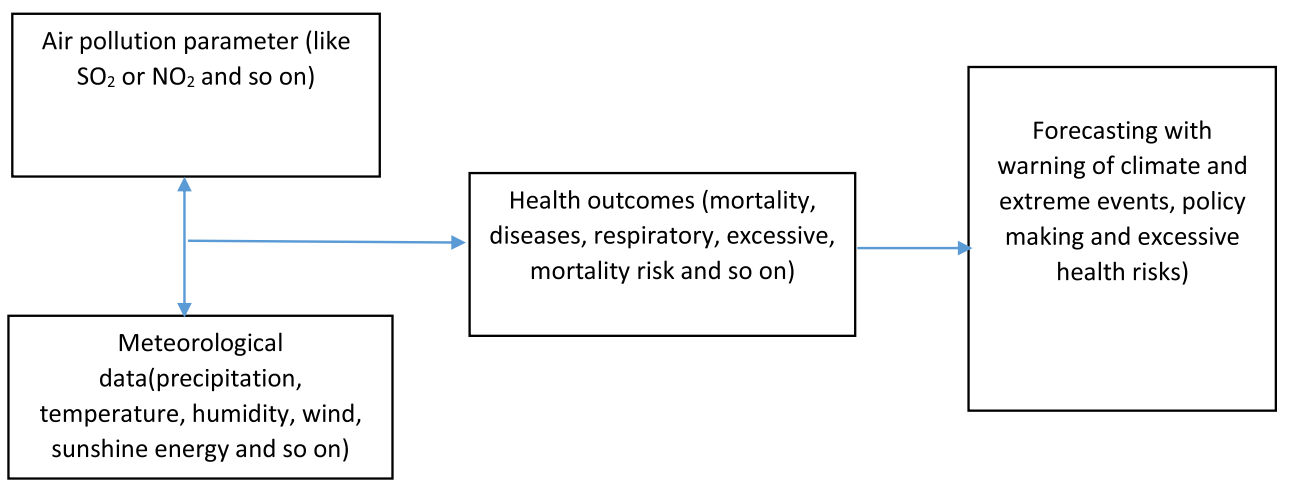

presence of suspended particles due to adsorption or reactions that are carried out with particles, the lungs penetrate deep into the lung and exacerbate pulmonary lesions and other complications. In the city of Khoozestan, the amount of oxides of sulfur in the months of October, November, December, January and February is not higher than the permitted $140 \mathrm{ppb}$.

There are seven types of nitrogen oxides that are important in human and $\mathrm{NO}$ and $\mathrm{NO}_{2}$ as airborne air and as an effective greenhouse gas for global warming.

The $\mathrm{NO}_{2}$ gas is poisonous and physiologically stimulates the respiratory tract, with more toxicity in comparison with NO.

Nitrogen oxides are first converted to $\mathrm{NO}_{2}$ by $\mathrm{NO}$ as a result of the combustion of nitrogen compounds and oxygen..

The effect of nitrogen oxides, including stimulation of pulmonary embolism, pupil eye dilatation, increased air resistance of the respiratory system, decreased gastrointestinal gas output, pneumonia development, increased acute bronchitis and nitrosamine production, throat and eye stimulation, coughing, shortness of breath, numbness and Fatigue.

Hydrocarbons and volatile organic compounds (VOC): These compounds are important in two aspects: first, they require the formation of photochemical oxidants, and secondly, certain types of cancer-causing compounds are known. There are several hundred compounds in this group, the most toxic of which is benzene, which is a transparent coating that plays an important role in human health. Benzene with a formula of $\mathrm{C}_{6} \mathrm{H}_{6}$ that has been used as a solvent in the past. Harmful and toxic cyber hydrocarbons include polychlorinated biphenyls, dioxins, eruptions, multi-core hydrocarbons, and aromatic hydrocarbons.

Aromatic hydrocarbons increase lung cancer, especially benzylation, stimulation of the eye through smogphotochemicals and stimulation of the mucosa and the effect of it into the centerpiece..

Ozone and other oxidants: Ozone is a very strong oxidant that is caused by exposure to sunlight with nitrogen dioxide and radical atomic oxygen in the air. This ozone is called tropophyre, which has been studied on a large number of people exposed to ozone (Zeng and Lu 2018). And specific pulmonary deficiencies have been observed. Epidemiologic studies on children have shown a decrease in the function of the lungs in concentrations of 200 micrograms per cubic meter or less. These changes will be exacerbated by the heat and the presence of other pollutants. Ozone breathing without any other oxidants also causes pulmonary discomfort even at low concentrations. In addition, early fatigue and reduced exercise records have been reported in areas with high ozone. The limit of tropospheric ozone concentration is ppb12 in one hour, and calculations show that the amount of ozone in the city of Isfahan was higher than the maximum in October, November, November, December and February.

Dust particles: Long contact with fine particles of dust is an important factor in the incidence of lung cancer and heart disease.

The dust consists of solid particles or liquid particles (aerosols) that form.

Hanging in the air. The pollutants can be adsorbed or mixed with dust, for example, sulfur anhydride is first dissolved in air humidity and then absorbed at the surface of the particles. Toxic materials in fossil fuels such as lead, nickel, iron, copper and other catalytic active materials are taken into account on the surface of incomplete fuel solids and pollutants. Between tires of cars with road surfaces and between car brakes and the bowl of the wheel adds a lot of toxic substances to the air in the form of walnuts. Heavy metals such as mercury, lead and chromium are produced in the metallurgy industry and small workshops of metallurgy, and pesticides and pesticides are one of the sources of pollutants in the form of dust and dust. Radioactive materials from nuclear facilities and radon gas are another source of dust pollution. Small particles (less than $5 \mu \mathrm{m})$ can be transmitted by the wind and some other atmospheric phenomena within a few hundred miles and staying in the air for several years.

Some particles of dust attack on the human body from the eyes and the skin begins to burn and allergy. Some chemicals such as mercury can enter the body directly from the skin. A part of dust particles (greater than $10 \mu \mathrm{m}$ ) are absorbed in the 
nose and throat mucous membranes. These particles may produce allergies and respiratory diseases. Also, the chemical substances along with these particles can enter the bloodstream. Toxins that enter the bloodstream thus spread throughout the human body and cause heart, liver, kidney, and other problems.

Some materials, such as heavy metals such as lead and mercury, are transported to the central nervous system by blood flow, causing neurological disorders and chronic depression. The natural dust from the desert is a dry matter and pollen from flowers and trees that generally have a diameter of more than $10 \mu \mathrm{m}$ and are taken in natural body filters. These particles, except in exceptional cases, do not pose a risk to human health. The risk of these particles is due to pollutants produced and added to humans.

It is believed that small particles that are caused by the combustion of fossil fuels are the most potent causative agent of cardiovascular complications among air pollutants. Pending particles cause more activity in the inflammatory and oxidative pathways. They do this by direct transferring into the bloodstream or by acting on the lung and releasing effective mediators.

\section{Effects of sunlight on diseases}

Any tissue capable of absorbing electromagnetic energy is called chromophore. The important ultraviolet chromophores are protein, yurcianic acid and nalalin. The action of absorption and chemical reaction varies in different parts of the body and depends on factors such as the thickness of the tissue (Ngwenya et al. 2018). The sun's ultraviolet radiation damages the synthesis of melanin. Creating a color, usually three days after the call, is observed, and it remains after a few days, and protects against ultraviolet radiation. More contact causes eritma (the characteristic of which is swelling in red), which may lead to blisters and scaling of the skin layer. The chronic effects of ultraviolet radiation include aging and skin cancer. Long-term exposure to extreme ultraviolet radiation causes skin dryness and shrinkage, which eventually results in cracking and infecting. Ultraviolet radiation can damage the cornea and lens of the eye. Contact with ultraviolet radiation affects the body's immune system, which results in the body losing its resistance to viral infections and bacteria. For example, activating a herpes virus on summer holidays is due to more exposure to ultraviolet radiation and the immune system (Holick 2016).

\section{The effect of climatic elements on the prevalence of diseases}

- effect of wind Wind or air turbulence is one of the climatic elements that causes Insomnia, insomnia, fatigue, muscle weakness, nervous stimulation, Spiritual anxiety, severe headache and pain in the wound sites after surgery there is a continuation of the wind in increasing or decreasing blood pressure. The sound of the wind blowing can disturb the hearing and cause the person to experience nervous weakness and nervous stimulation. Winds in cities and villages in arid areas cause dust, respiratory disorders, eye diseases such as trachoma, tiredness, etc., or diseases such as tuberculosis. The wind is capable of transmitting some diseases, including eggs of parasites, various sprays, tetanus and shark, easily from an infected point to a healthy spot and is effective in flying anopheles mosquitoes (Ellwanger and Chies 2018)..

- effect of heat Human beings are affected by ambient temperature in any situation.

It's yours. High temperatures cause metabolic and, in some cases, drought Breathes. Because the heat generated in the body, which is the result of the internal metabolism, must be removed from the body. If heat exchanges encounter problems, the living creature will be weakened and ready to develop various diseases. For this reason, physicians are urging cardiac patients to avoid getting hot in hot weather because of hot air activity and increased heart rate, and with prolonged heat, the heart becomes tired and permanently weakened (Cao et al. 2018). To be Excessive heat causes the veins to loosen and swell the bloodstream under the skin. Transpiration is increased and evaporation causes cooling of the body, but this sweat is accompanied by sodium and other salts, excessive sodium deficiency causes severe muscle contraction and weakness and fatigue. Disposing of other salts also causes anemia. The heat-affected person has serious or mild injuries in terms of heat intensity, bearing capacity and time of stopping in the heat, which include:

Feeling weak and helpless, reducing work capacity, reducing voluntary activities and skin congestion (lack of blood and oxygen to the skin). Increased heart rate, severe muscle pain, dyspnea, dizziness, vomiting, severe muscle contractions, and severe psychological reactions that result in death. Excessive hemorrhage has an adverse effect on spermatozoids' manufacturing devices. High heat causes inflammation of the sweat glands, sweating and nerve weakness and stomach upset, resulting in digestive problems, absorption and food intake. In hot climates, blood pressure is lower and blood volume is increased by drinking more fluids, resulting in dilution of the blood. But excess water is eliminated by sweating, with the sweat of the necessary salts in the blood to escape from the plasma and the quality and quantity of blood fluctuate, and these changes reduce the body's resistance to microbes, especially infectious diseases.

Effect of cold As soon as the person feels cold, the body is defensive and immediate metabolism increases. But if you keep cold, there's another protective mechanism that increases the thyroid gland secretion of the thyroid gland (Martinez 


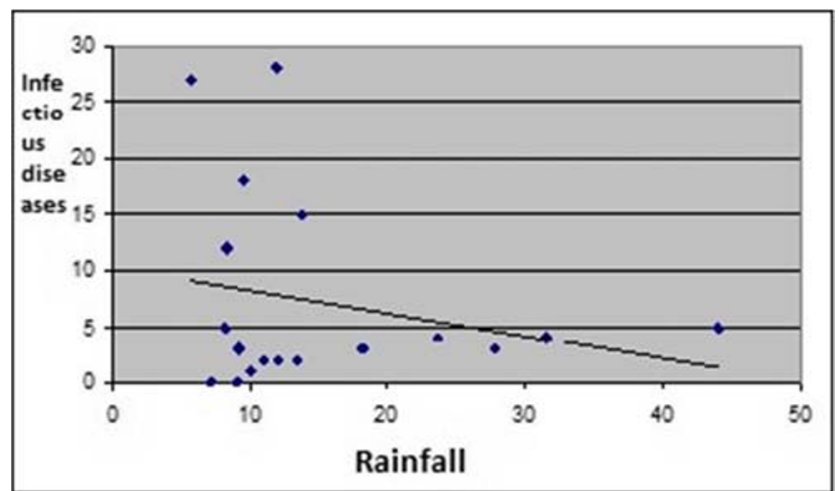

Fig. 2 Relationship between the deaths due to infectious diseases and diabetes mellitus and annual precipitation

et al. 2018). The continuous stimulatory effects of cold on the thyroid gland justify the higher prevalence of toxic toxicity in cold regions than in warmer areas.

The skin around the body has a system that runs against the colds Slam against heat. The system is operating at $+15^{\circ} \mathrm{C}$. However, when the temperature of the environment continues to drop, the risk of frostbite on the toes and the hands, lips and nose and the ears is created, and the stenosis system of the veins performs inversely and begins to dilate. The affected member then suffers from blisters similar to burns. In the cold seasons most cases of colds, flu, arthritis and Joint pains, sinusitis, bronchitis and pneumonia, asthma, and heart failure can be observed.

Climate is one of the most effective structural elements of the planet, and undoubtedly nature, man and all life are at a widespread level influenced by climatic conditions. Climate as an old discipline combined with detailed scientific research with other disciplines, including agriculture, forestry, hydrology, geology, transportation, urbanization, health, diseases, etc. (Błażejczyk et al. 2018). Therefore, the environment and humanity are affected by a large variety of weather conditions. The World Health Organization has defined health as "a state of complete physical, mental, social, and not merely lack of disease and weakness." Undoubtedly, the particular aspects of

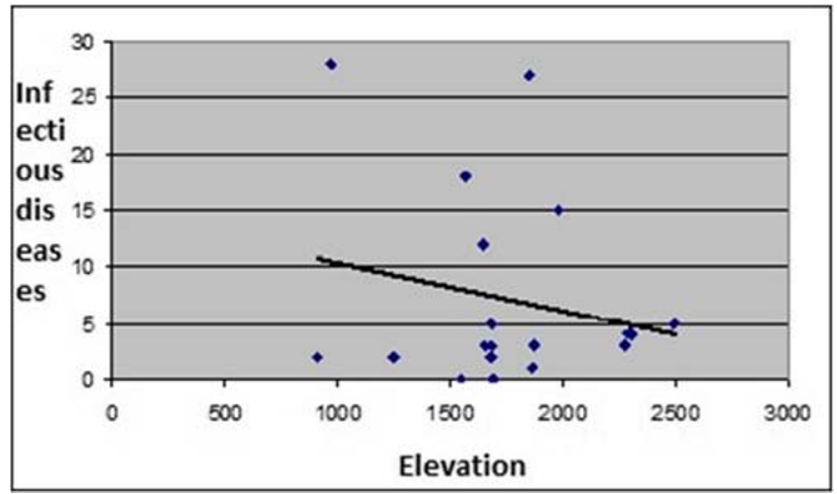

Fig. 3 Relationship between the deaths due to infectious diseases and diabetes mellitus and elevation

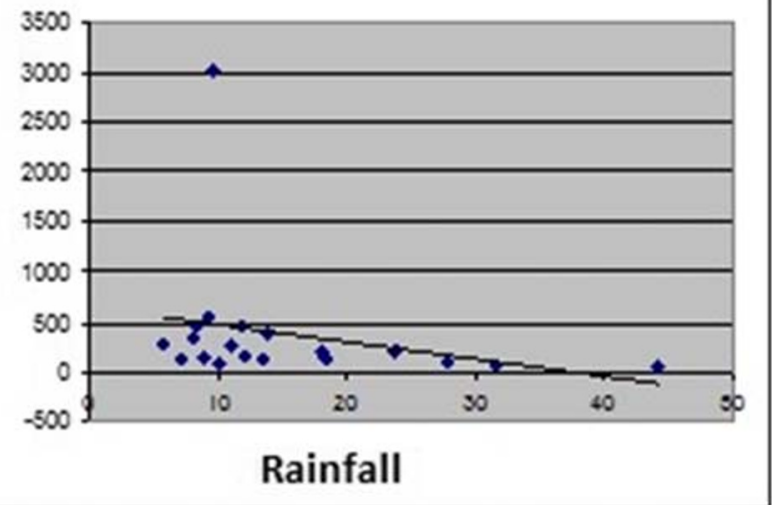

Fig. 4 Relationship between deaths due to cardiovascular disease and annual precipitation

this health are sensitive to climate and climate. For example, heart disease often occurs in people who are exposed to extreme pressure from extreme heat or cold.

Applied climatic climates are used to realize many goals such as economic and medical and so on among the most effective climatic elements, two elements of temperature and precipitation are among the most important variables in the field of medicine, and have a significant impact on human disease. In fact, any change in the amount of these two factors can reduce or increase the incidence of human diseases such as cardiovascular, respiratory, digestive and other diseases. In this regard, another important issue that has already been addressed by the applied climatic environment is the problem of air pollution. Air pollutants include dust, gases, smoke and vapors, carbon fumes, radioactive particles and chemicals, and so on for human life, plants and animals are dangerous, harmful and disruptive to their comfortable lives. The medical geology of science is the study of the relationship between the phenomena of the planet and the dispersion of diseases (Arrizabalaga 2018). Discussions and studies have been carried out on the definition and scope of medical geography.

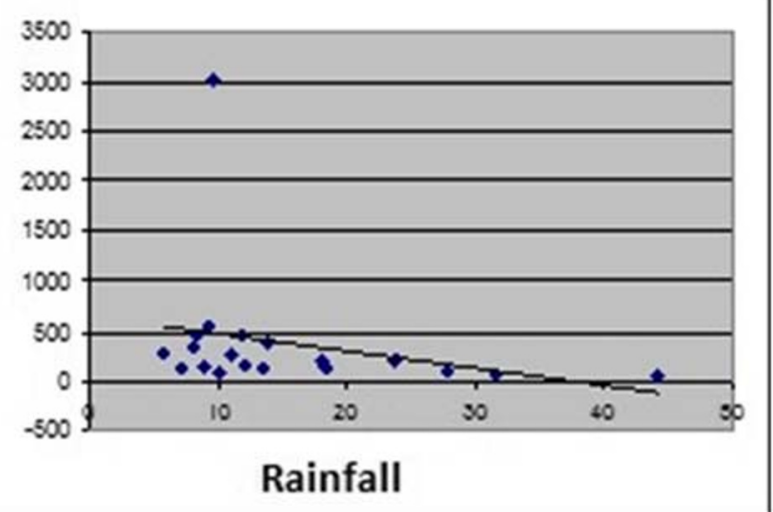

Fig. 5 Relationship between deaths due to cardiovascular disease and average annual temperature 


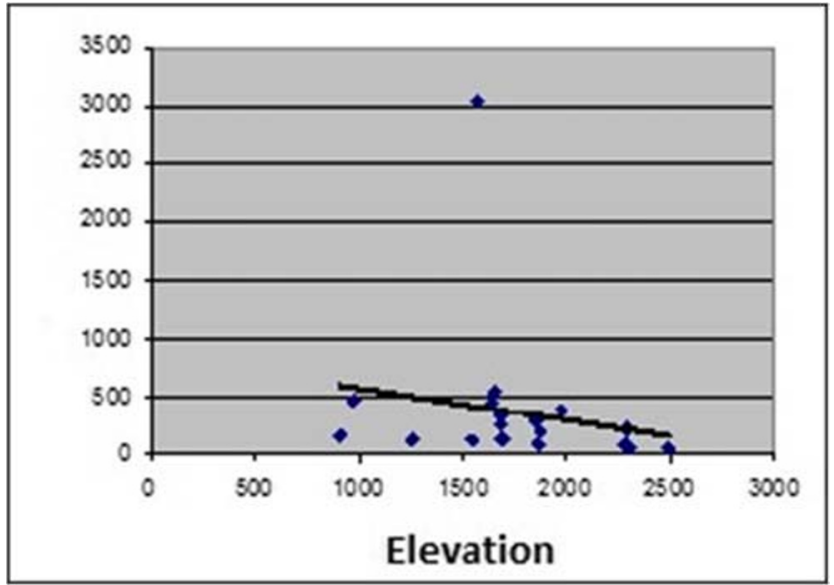

Fig. 6 Relationship between deaths of cardiovascular disease and height

Filippelli et al. (2018) in a study on the relationship between climate factors and air pollution and the number of patients with myocardial infarction in Indiana, it was concluded that an increase in the number of patients referred to hospitals according to the increase in the amount of contaminants, especially carbon monoxide (CO), Nitrous oxide (NO) and sulfur dioxide $\left(\mathrm{SO}_{2}\right)$. Also, the number of visitors in winter is higher due to the frequency and variety of inertia, long nights, and increased air pollution.

Barnes (2018) in another article about the relationship between temperature components and hours of sunlight, day length and suicide rates, showed that daily suicides of the weekly, fifteen Daily, monthly and seasonal correlations with temperatures, sunshine and daylight hours have a positive correlation with the highest suicide rates for July.

Baysan and Burke 2018 In a study entitled "The Study of Psychosocial Factors in Suicide Being in One Year 20172018, concluded that the highest suicide rate occurred in the age group of 15-24 years and 58\% of suicides In the first half of the year (half warm), drug use was the most common suicide attempt in this province.

The study of the impact of pollutants on human health has also led to a number of studies on various methods and

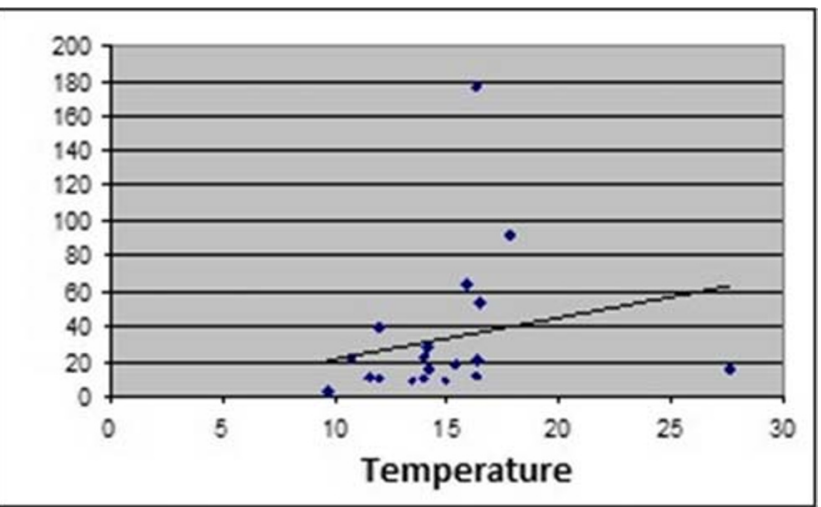

Fig. 7 Relationship between deaths due to cardiovascular disease and average annual temperature

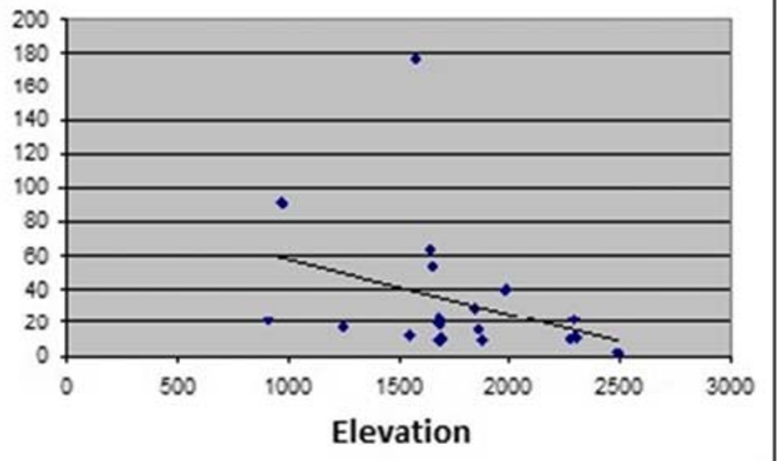

Fig. 8 Relationship between deaths due to cardiovascular disease and height

practices in the world, which is briefly discussed (Requia et al. 2018). In Athens, the association of deaths for various causes over four years (1984-1988) has been investigated with concentrations of contaminants. The pollutants included carbon monoxide $(\mathrm{CO})$, sulfur dioxide $\left(\mathrm{SO}_{2}\right)$ and black carbon smoke. These pollutants were obtained from five metropolitan stations and their daily mean values, and the effects of temperature and humidity have been investigated, all of which have been correlated, but when the two parameters of temperature and humidity were eliminated, observation It was found that concentrations of $\mathrm{SO}_{2}$ and smoke are more related to daily mortality.

In the United Kingdom, research has been conducted on the effects of air pollution on the number of hospital admissions due to acute asthma attacks and acute respiratory tract infections over the two years (1990-1998), and concluded that in the autumn and spring seasons the relationship between $\mathrm{SO}_{2}$ and smoke and there are no asthma attacks with those hospitalized (Williams et al. 2018). But in the winter there was a significant relationship between $\mathrm{SO}_{2}$ and smoke and hospitalization. But at this time, temperature, pressure and air humidity parameters were eliminated. Also, there was a significant relationship between the average weekly $\mathrm{SO}_{2}$ and the average weekly visitors due to respiratory diseases in the fall and winter. It is also observed that smoke concentration can be

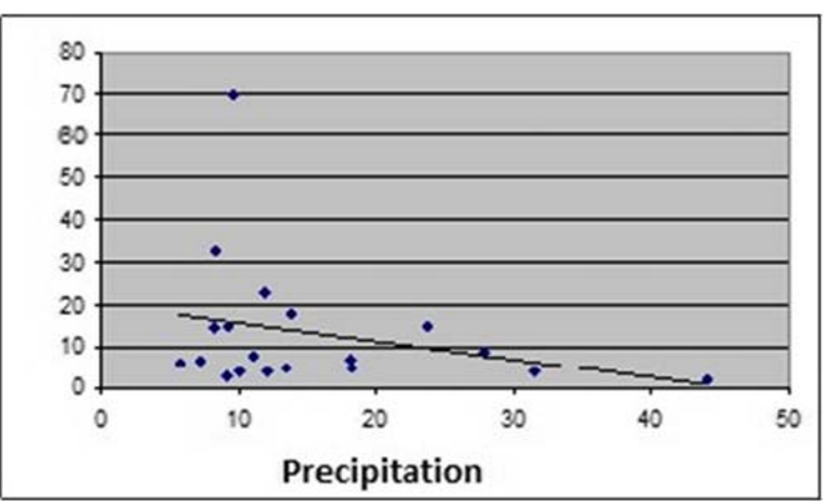

Fig. 9 Relationship between deaths due to gastrointestinal diseases and annual mean precipitation 


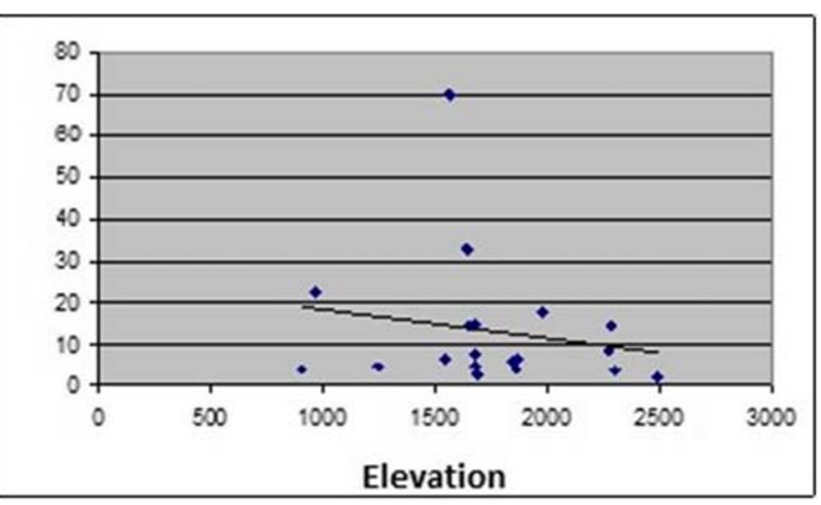

Fig. 10 Relationship between deaths due to gastrointestinal diseases and altitude

recognized as a predictor of asthma and respiratory diseases, and an increase in every $100 \mathrm{ug} / \mathrm{m}^{3}$ smoke concentrations in the winter causes an increase in more than 5 cases of asthma admission daily, as well as an increase of $100 \mathrm{ug} / \mathrm{m}^{3}$ at $\mathrm{SO}_{2}$ concentration, it increases the number of asthma patients every day (Poole et al. 2019).

In Barcelona, Spain, the association of pollutants such as $\mathrm{SO}_{2}, \mathrm{NO}_{2}, \mathrm{O}_{3}$ and black smoke with asthma patients to hospitals over five years (1989-1989) has been investigated. In this study, patients under the age of 14 years and over 65 years have not been considered (Achebak et al. 2018). This study concluded that the black smoke concentration was significantly correlated with emergency patients due to asthma only in summer, and this relationship was more strongly observed between the three-day average of black smoke and patients and $\mathrm{NO}_{2}$ was the only pollutant It has a direct relationship with asthma patients in the summer and in winter, and there is no relationship between ozone and $\mathrm{SO}_{2}$ with those who have had an acute attack on the name.

\section{Methodology}

In the present study, library and documentary methods have been used. Information about the climatic elements from the

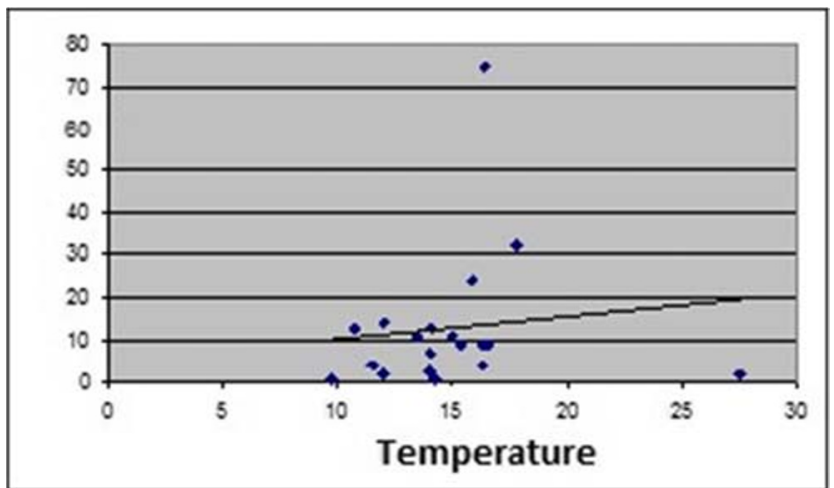

Fig. 11 Relationship between mortality from cardiovascular disease and annual temperature

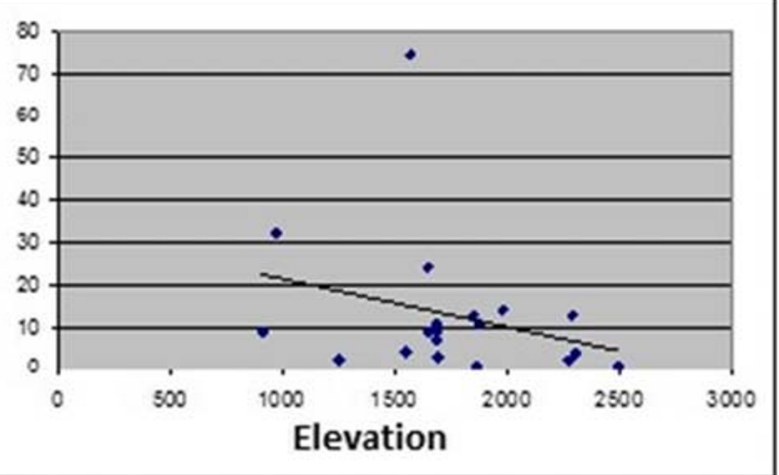

Fig. 12 Relationship between deaths due to cardiovascular disease and height

Meteorological Organization of Iran and the data banks of this organization have been extracted. Information about the deaths due to illnesses in Khoozestan province was extracted from a report on the statistics of health affairs, Ministry of Health and Medical Education during a period of 5 years 1381-1386. The climatic zoning of Khoozestan province was carried out based on the Ambarage model. Khoozestan province was divided into three climatic regions: desert, dry and semi-arid. Data analysis and statistics were collected using ARCGIS and Minitab softwares. The relationship between variables was estimated using correlation coefficient. Then, according to the climatic regions using GIS, the distribution and spatial distribution of various diseases in the form of the map was analyzed.

\section{Results}

\section{Infectious and parasitic diseases}

These diseases include pulmonary tuberculosis, tetanus, myasthenia, typhoid, intestinal infections, viral meningococcal hepatitis and viral hemorrhagic fever. As shown in the

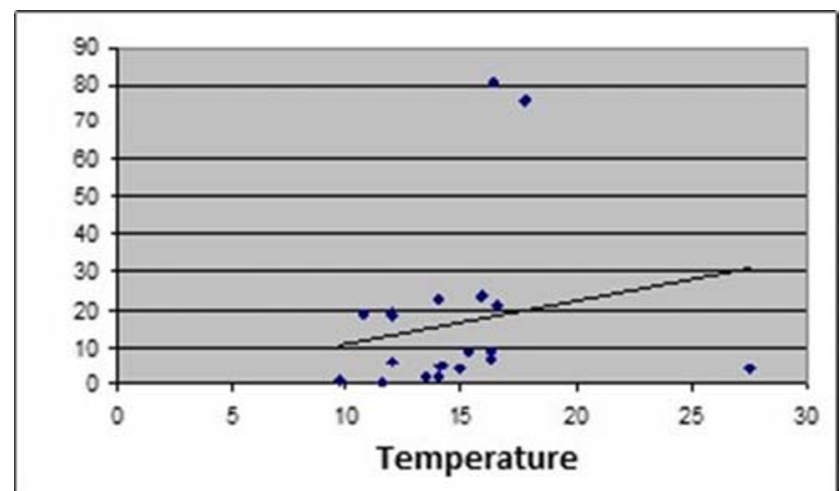

Fig. 13 Relationship between deaths due to birth-related illnesses and annual average temperature 


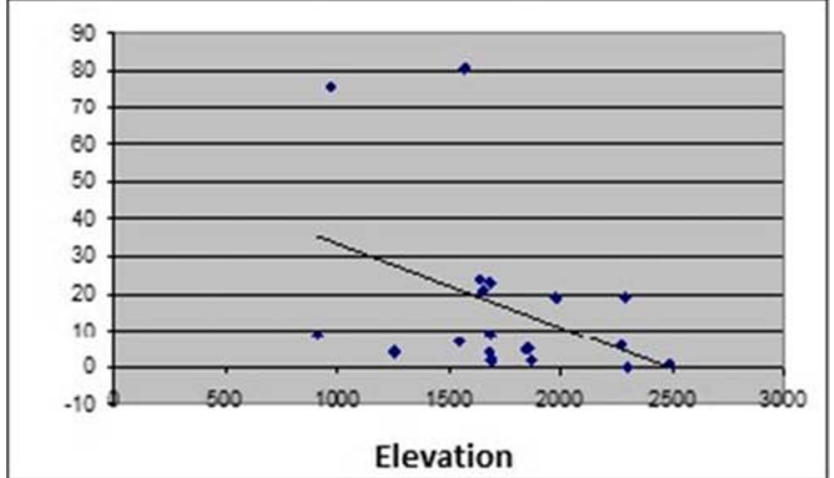

Fig. 14 Relationship between deaths due to illnesses around birth and height

diagrams, there is a reciprocal relationship between precipitation and infectious and parasitic diseases at the level of $01 /$ with a value of 451 / so with increasing or decreasing precipitation the infectious and parasitic infections increases can increase or decrease.

It also decreases with an increase in the height of infectious and parasitic diseases. This relationship is significant at -0.55 and (525). There is no significant relationship between temperature and disease variables.

Figures 2 and 3 show respectively the relationship between precipitation and elevation of the area (that effect on air humidity and air pressure) and the number of deaths due to infectious and parasitic diseases.

The figures also shows the spatial dispersion of infectious and parasitic diseases in relation to the climatic zoning of Ambergae. As we can see, we are witnessing the highest density of diseases in the desert areas, and as far as the west and the semi-arid regions of the province move from this and the amount is reduced.

\section{Cardiovascular disease}

This group of diseases includes heart valve rhythm disorders, heart failure and other heart disease. Figures 4, 5 and 6

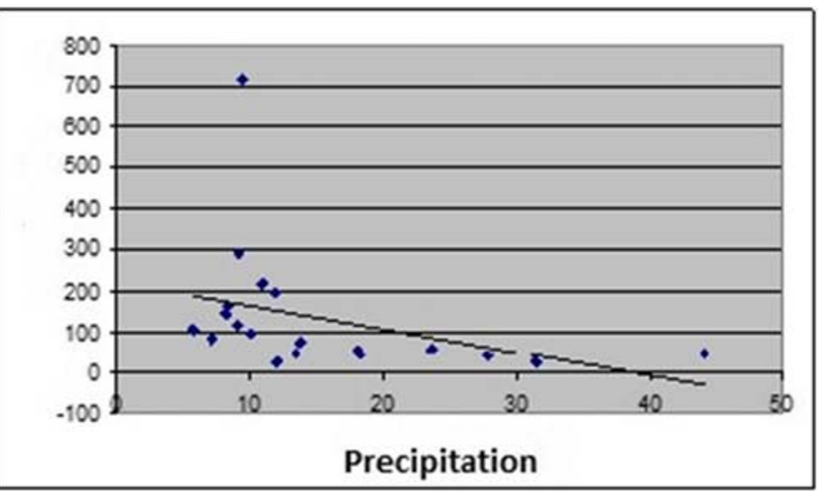

Fig. 15 Relationship between deaths due to badly defined symptoms and ill-defined and ambiguous annual mean precipitation

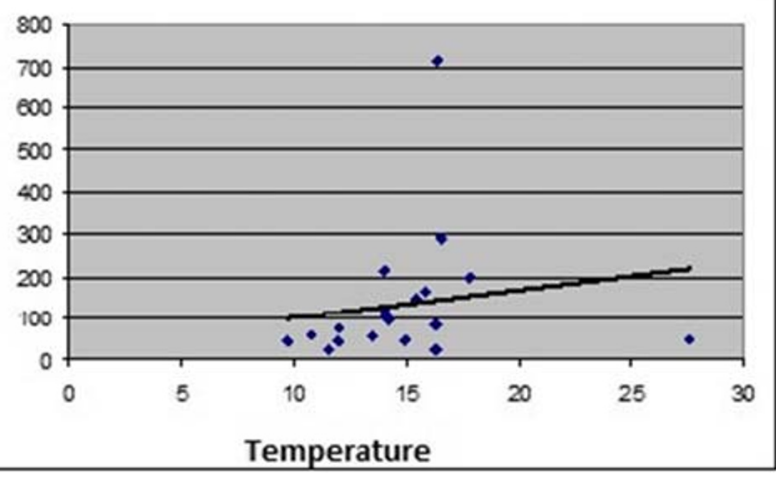

Fig. 16 Relationship between deaths due to badly defined symptoms and ill-fated states and ambiguous average annual temperatures

illustrate the relationship between precipitation, temperature and height, and deaths from cardiovascular disease. Be According to the aforementioned diagrams, the number of deaths due to cardiovascular disease with temperature and altitude at 05.05 has a direct and significant relationship with the values of 623 and 521, respectively. Also, the causal relationship has a direct and significant relationship with the level 01 / with a value of $472 /$. Figures 7 and 8 showed that the density of this disease in the desert areas of the province, especially in the city of Isfahan, and the more close to the dry and semi-arid areas, decreases the density of these diseases.

\section{Gastrointestinal diseases}

It includes focal, stomach and duodenal ulcers, abnormalities, gallbladder and pancreatic disease, and liver disease. Figures 9 and 10 show, respectively, the relationship between the three climatic elements of precipitation, height, and deaths of the disease. As it is deduced from the diagrams, there is an inverse and significant relation between the elements of precipitation and height and the number of deaths with the values of 471 and $-486 /$ - at the level of 01 /. As seen in these figures, the distribution of the dead in the desert and dry areas of the province is more than semi-arid areas.

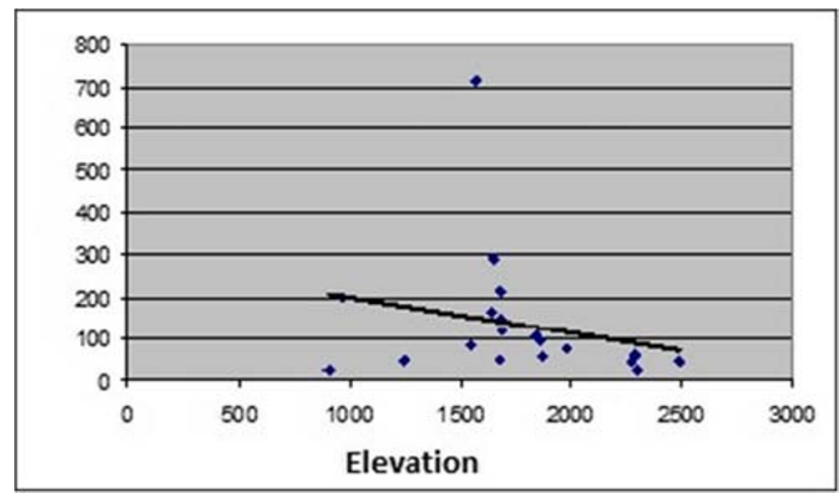

Fig. 17 The connection between the dead is due to badly defined and vague symptoms and altitudes 


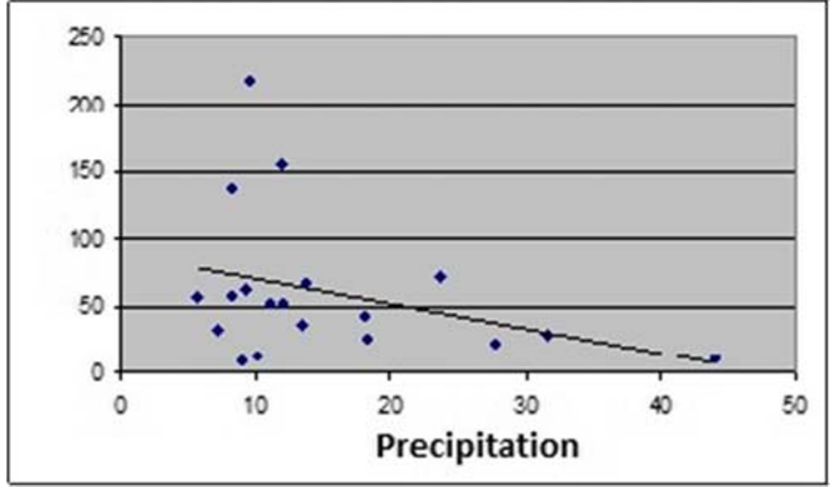

Fig. 18 Relationship between deaths due to cancerous diseases and annual precipitation

\section{Urinary tract diseases}

This group of diseases includes nephrotic syndrome of other diseases of the urinary tract. As diagrams Figs. 11 and 12 indicate that there is a negative and significant correlation between the climate elements of height and the deaths of the disease with a value of 535 / - with a positive correlation of 457 / with temperature.

\section{Diseases around birth}

Includes maternal and pregnancy problems caused by the placenta and its appendages due to the length of pregnancy and embryo development, labor injuries, respiratory and vascular disorders in the baby, infant and infant infections, blood and coagulation disorders in the baby and fetus, endocrine disorders, and Metabolic, Temperature disorders in the baby and gastrointestinal disorders in the fetus and the infant. Figures 13 and 14 show the relationship between the deaths due to birth-related illnesses and climatic elements. In these diseases, by increasing the height, the number of deaths caused by this disease is reduced and increased by increasing

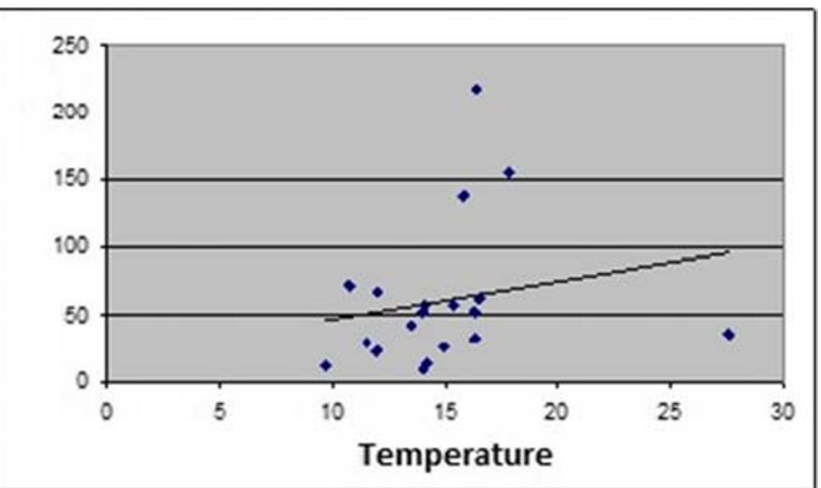

Fig. 19 Relationship between deaths due to cancer and average annual temperatures

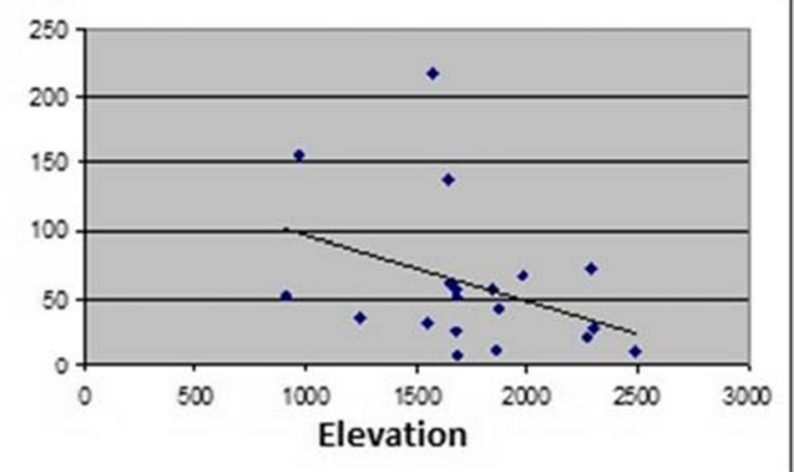

Fig. 20 Relationship between deaths due to cancer and height

the temperature of this amount. The correlation values achieved in the order of 623 are at the level of $05 /$ and 470 / at the level of $01 /$. The density of these diseases in the desert areas of the province is more than dry areas and in dry areas more than semi-arid regions. The east of the province decreases the temperature and increases the amount of precipitation and elevation.(Figs. 15, 16 and 17)

\section{Symptoms and bad situations are defined and vague}

This category of patients includes aging without dementia, sudden death of the baby and seizures caused by fever and temperature. Diagrams 15, 16 and 17 show a positive correlation between temperature and negative correlation between height and precipitation and death due to ill-defined symptoms and ill-defined conditions. The amount obtained for the operating temperature of 450 / at the level of $01 /$ and for precipitation and elevation is $-725 /-521 /-05$, respectively.

\section{Cancerous diseases}

These diseases include skin and dermal, lips and mouth, esophagus, stomach, liver and bile ducts, pancreas, intestines, larynx, lungs and bronchus, chest, cervix, ovary, bladder, prostate, kidney, lutetium, mullet of myelos, Brain, lymphoma and Hodgkin's disease. In this case, Figs. 18, 19, and 20 show a direct relationship between temperature with a value of 526 at the level of $05 /$, and the indirect relationship between precipitation and elevation with values of $745 /$ - and $625 /$ - at the level of 05 / with the number of deaths from cancerous diseases.

\section{Conclusion}

Climatology is a discipline associated with other parameters, for example, mining, geology, transportation, urbanization, health, and health. This knowledge can control many human 
needs and adaptations. One of the most important issues related to climate today is the discussion of the changes and dispersion of various diseases. In this research, cluster elements and the number of deaths due to common diseases in Isfahan province were surveyed. The findings suggest that there is a positive and significant relationship between the number of deaths due to gastrointestinal diseases, infectious and parasitic diseases, cardiovascular disease and temperature. As the temperature increases, the number of deaths caused by these diseases increases. In other diseases, there is a positive relationship between the number of deaths and temperature. Also, there is a significant negative correlation between the number of deaths caused by cardiovascular diseases, urinary tract disease and precipitation, so that the number of deaths decreases with increasing rainfall, as well as between urinary tract disease, cardiovascular disease and altitude. In general, as you move from the maps, moving from the east to the west of the province reduces the number of deaths. Therefore, the allocation and distribution of resources (budgets, manpower, equipment) through assessment of regional health needs in tropical areas can help reduce the number of deaths due to common diseases. Also, rapid diagnosis of epidemics and their timely control by location determination residence of patients with an epidemic can predict how the disease spreads and to take precautionary measures in places at risk. Therefore, establishing an appropriate and efficient communication network between different health centers and institutions can help us to achieve this. Also, prediction of health events can be done by using modeling techniques to control the development, spreading and combating of these diseases. It is therefore useful to predict health events by using modeling techniques in disease management. Also planning in the field of health services (location of facilities and service centers, prediction over time of assessing the status of existing and future) is another notable advantage.

Authors' contributions Safieh Javadinejad designed this research and she wrote this paper and she collected the necessary data and she did analysis of the data.

Rebwar Dara participated in drafted the manuscript and he contributed in the collection of data and interpretation of data and edited the format of the paper under the manuscript style.

Forough Jafary participated in the data collected and data analysis.

Funding information We thank Esfahan Regional Water Authority for funding this study to collect necessary data easily and helped the authors to collect the necessary data without payment, Mohammad Abdollahi and Hamid Zakeri for their helpful contributions to collect the data. All other sources of funding for the research collected from authors.

\section{Compliance with ethical standards}

Conflict of interest "The authors declare that they have no competing interests."
Open Access This article is licensed under a Creative Commons Attribution 4.0 International License, which permits use, sharing, adaptation, distribution and reproduction in any medium or format, as long as you give appropriate credit to the original author(s) and the source, provide a link to the Creative Commons licence, and indicate if changes were made. The images or other third party material in this article are included in the article's Creative Commons licence, unless indicated otherwise in a credit line to the material. If material is not included in the article's Creative Commons licence and your intended use is not permitted by statutory regulation or exceeds the permitted use, you will need to obtain permission directly from the copyright holder. To view a copy of this licence, visit http://creativecommons.org/licenses/by/4.0/.

\section{References}

Achebak H, Devolder D, Ballester J (2018) Heat-related mortality trends under recent climate warming in Spain: A 36-year observational study. PLoS Med 15(7):e1002617

Analitis A, De'Donato F, Scortichini M, Lanki T, Basagana X, Ballester F et al (2018) Synergistic Effects of Ambient Temperature and Air Pollution on Health in Europe: Results from the PHASE Project. Int J Environ Res Public Health 15(9):1856

Arrizabalaga J (2018) At the intersection of medical geography and disease ecology: Mirko Grmek, Jacques May and the concept of pathocenosis. Hist Philos Life Sci 40(4):71

Barnes CS (2018) Impact of Climate Change on Pollen and Respiratory Disease. Curr Allergy Asthma Rep 18(11):59

Baysan C, Burke M, González F, Hsiang S, Miguel E (2018) Economic and Non-Economic Factors in Violence: Evidence from Organized Crime, Suicides and Climate in Mexico (No. w24897). Natl Bur Econ Res

Błażejczyk K, Baranowski J, Błażejczyk A (2018) Climate related diseases. Current regional variability and projections to the year 2100 . Quaest Geogr 37(1):23-36

Buchner R, Nair I, Pinto B (2018) Unintended consequences of dams and water security: an insight into women's vulnerability and the spread of malaria in Ethiopia. In: Water, Climate Change and the Boomerang Effect. Routledge, pp 173-197

Cao Q, Yu D, Georgescu M, Wu J, Wang W (2018) Impacts of future urban expansion on summer climate and heat-related human health in eastern China. Environ Int 112:134-146

Ellwanger JH, Chies JA (2018) Wind: a neglected factor in the spread of infectious diseases. Lancet Planet Health 2(11):e475

Filippelli GM, Mark TP (2018) Addressing (pollution-related global environmental health burdens. GeoHealth 2 (1):2-5

Holick MF (2016) Biological effects of sunlight, ultraviolet radiation, visible light, infrared radiation and vitamin $\mathrm{D}$ for health. Anticancer Res 36(3):1345-1356

Martinez GS, Diaz J, Hooyberghs H, Lauwaet D, De Ridder K, Linares C, ..., Adamonyte D (2018) Cold-related mortality vs heat-related mortality in a changing climate: A case study in Vilnius (Lithuania). Environ Res 166:384-393

Mills BJ, Krause AJ, Scotese CR, Hill DJ, Shields GA, Lenton TM (2018) Modelling the long-term carbon cycle, atmospheric CO2, and Earth surface temperature from late Neoproterozoic to present day. Gondwana Res

Ngwenya B, Oosthuizen J, Cross M, Frimpong K (2018) Emerging heatrelated climate change influences; a public health challenge to health care practitioners and policy makers: Insight from Bulawayo, Zimbabwe. Int J Disaster Risk Reduct 27:596-601

Poole JA, Barnes CS, Demain JG, Bernstein JA, Padukudru MA, Sheehan W, ..., Cohn JR (2019) Impact of weather and climate 
change with indoor and outdoor air quality in asthma. J Allergy Clin Immunol

Ramadour M, Burel C, Lanteaume A, Vervloet D, Charpin D, Dutau H, ..., Vervloet D (2000) Prevalence of asthma and rhinitis in relation to long-term exposure to gaseous air pollutants. Allergy. 55(12):11631169

Requia WJ, Mohamed M, Higgins CD, Arain A, Ferguson M (2018) How clean are electric vehicles? Evidence-based review of the effects of electric mobility on air pollutants, greenhouse gas emissions and human health. Atmos Environ

Vezzulli L, Grande C, Reid PC, Hélaouët P, Edwards M, Höfle MG, ..., Pruzzo C (2016) Climate influence on Vibrio and associated human diseases during the past half-century in the coastal North Atlantic. Proc Natl Acad Sci 113(34):E5062-E5071

Wei Q, Wu J, Zhang Y, Cheng Q, Bai L, Duan J et al (2019) Short-term exposure to sulfur dioxide and the risk of childhood hand, foot, and mouth disease during different seasons in Hefei, China. Sci Total Environ 658:116-121

Williams ML, Lott MC, Kitwiroon N, Dajnak D, Walton H, Holland M et al (2018) The Lancet Countdown on health benefits from the UK Climate Change Act: a modelling study for Great Britain. Lancet Planet Health 2(5):e202-e213

Wu X, Lu Y, Zhou S, Chen L, Xu B (2016) Impact of climate change on human infectious diseases: Empirical evidence and human adaptation. Environ Int 86:14-23

Zeng J, Lu J (2018) Mechanisms of action involved in ozone-therapy in skin diseases. Int Immunopharmacol 56:235-241

Zhengdong Z, Guangcai W, Xiaohui H, Zhichao S (2018) Quantitative Analysis of Influencing Factors of Air Pollution and Evolution Law of Nitrogen Oxide Distribution in Beijing, Tianjin and Hebei. Am J Environ Sci Eng 2(4):65-71 